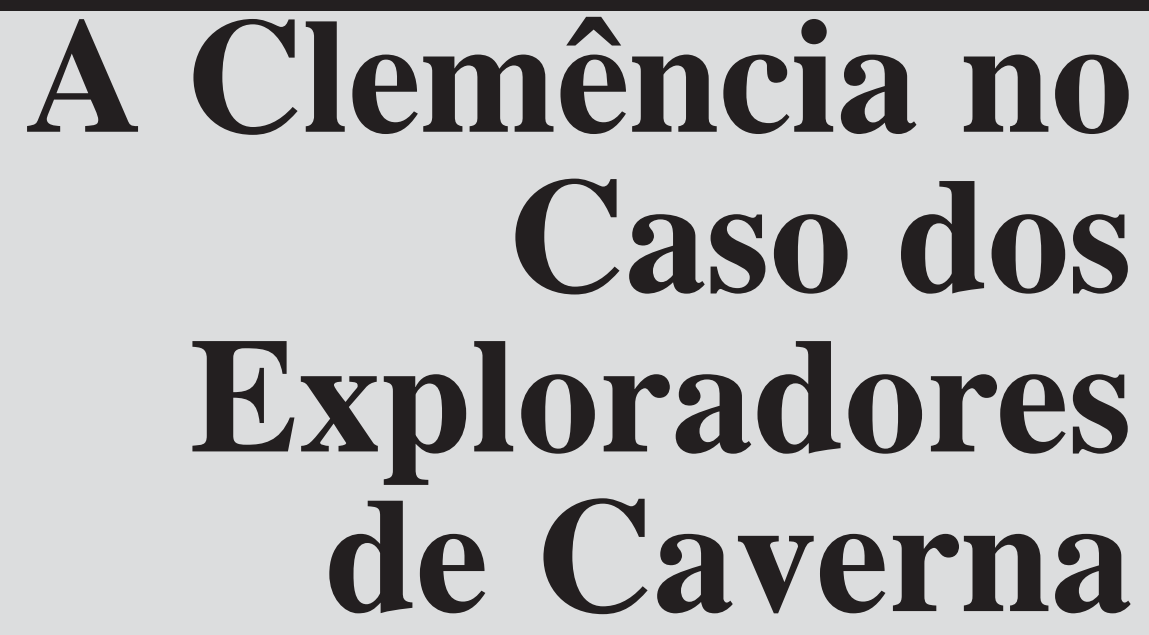

Sâmia Regina Feitoza do Nascimento 



\section{A Clemência no Caso dos Exploradores de Caverna}

\section{œ INTRODUÇÃO}

O Caso dos Exploradores de Cavernas é uma ficção elaborada pelo jurista e professor de Jurisprudence da Harvard Law School, Lon L. Fuller, baseada em dois casos verídicos que tem em seu tema central a antropofagia como forma de sobrevivência. Os casos U.S vs. Holmes (1842) e Regina vs. Dudley \& Stephens (1884) têm como diferencial, quanto ao livro, o ambiente onde ocorreram. Estes têm a antropofagia realizada entre vítimas de naufrágios, enquanto o dos exploradores de caverna, aborda uma seqüência mais dramática e claustrofóbica, uma vez que as vítimas foram soterradas em uma gruta, durante uma expedição.

Pode-se facilmente perceber que os fatos que enriquecem a obra de Fuller são emprestados destes dois casos: o estado de desespero e da falta de esperança dos envolvidos, a escolha da vítima pela sorte, o homicídio seguido de canibalismo (em um dos casos), a simpatia dos réus e a comoção popular provocadas na sociedade, defesas baseadas no estado de necessidade, condenações no júri e até a possibilidade de perdão.(ROSSI, 2003, p.08).

A princípio, o livro, traduzido para o português pelo professor Paulo Faraco de Azevedo, pode parecer insólito, porém, leva a uma profunda reflexão sob todos os aspectos, morais, éticos, sociológicos, filosóficos e científicos. Não é necessário que o leitor seja iniciado no Direito para ter total compreensão da situação e possa formar sua opinião. Nosso contato com o caso, por exemplo, se deu pela apresentação do trabalho " $A$ Visão de Truepenny", apresentado pelos alunos do primeiro semestre (2004.1) da Faculdade 7 de Setembro, na disciplina Introdução ao Estudo do Direito-I, tendo como autores originais, os alunos: Denis Damasceno Ramos, Gardênia Marques, Giovanna Bezerra, Ginna Passos, Kamilla Nocrato Loiola, Lina Mara Freitas Pimentel, Mila Ramalho, Natália Ives, Samia Regina Feitoza do Nascimento e Taísa Vasconcelos. 
Nesta nova abordagem sobre o tema, pretende-se reforçar os argumentos que defendem o posicionamento do hipotético Presidente C.J. Truepenny, inseridos no caso original como defensor do pedido de Clemência ao Executivo, em prol dos espeleólogos, como a solução mais razoável para o caso, devido à sua singularidade, em detrimento dos demais posicionamentos.

\section{Co DesenVolvimento}

\subsection{O Caso}

No mês de Maio do ano de 4299, os réus, membros da Sociedade Espeleológica, entidade amadora destinada à exploração de cavernas, juntamente com a vítima Roger Whetmore, também membro de tal organização, adentraram em mais uma caverna a ser conhecida e explorada pelo grupo, quando, logo na entrada, foram surpreendidos por um deslizamento de terra. $\mathrm{O}$ fato ocasionou a queda de enormes pedras que, por sua vez, bloquearam a única entrada conhecida da caverna.

Após analisarem a situação os exploradores decidiram-se por ficar onde estavam, pois sabiam que caso seu retorno tardasse uma equipe de resgate seria enviada ao local. O que de fato ocorreu, logo que as famílias dos membros da expedição notificaram o secretário da Sociedade do não retorno destes às suas casas.

Com as coordenadas deixadas pelos espeleólogos na sede da Sociedade, uma equipe de resgate conseguiu chegar ao local. Porém dificuldades foram encontradas nas tentativas de remoção das pedras, ocorreram novos desmoronamentos e dez trabalhadores foram soterrados. Enormes gastos foram feitos nas tentativas de resgate, inclusive, por subscrição popular e concessão Lesgilativa.

A comunicação foi estabelecida no vigésimo dia, através de um aparelho capaz de receber e enviar mensagens, carregado pelos exploradores, $\mathrm{e}$ de um semelhante colocado no exterior da caverna. A real situação dos espeleólogos foi apresentada, suas provisões, já sabidas escassas, chegaram a um nível crítico e foi constatada a não existência de animais e vegetais, no interior da caverna, que pudessem lhes servir de alimento.

Dada a situação, os exploradores questionaram qual o tempo estimado para o resgate. Era de dez dias, naquele momento. Após essa informação, solicitaram a opinião médica sobre suas chances de sobrevivência, por esse período, com as provisões restantes. A resposta foi de que seriam ínfimas. Em seguida, as comunicações cessaram por oito horas. 
De seu retorno, Roger Whetmore, falando em nome dos demais membros da expedição, questionou aos médicos presentes se seria possível a sobrevivência através da ingestão da carne de um dos membros. Relutante, o Chefe dos Médicos respondeu positivamente. Whetmore, então, indagou se seria aconselhável a escolha da vítima pela sorte, desta vez, o Chefe dos Médicos não respondeu, assim como as outras autoridades presentes (autoridades do governo e religiosas). As comunicações cessaram novamente e presumiu-se, erroneamente, que as baterias do comunicador haviam acabado. Do resgate dos exploradores descobriu-se que no vigésimo terceiro dia Roger Whetmore foi morto e devorado por seus companheiros.

Dos depoimentos, apurou-se que foi Whetmore quem primeiro propôs a resolução para o problema e o método a ser utilizado para a escolha da vítima, fornecendo inclusive a ferramenta utilizada para tal. Os réus, a princípio, relutaram, mas após as comunicações relatadas, concordaram com a idéia, que por sua vez foi rejeitada por Whetmore na hora de ser colocada em prática. Os réus o acusaram de "quebra de boa vontade" (FULLER, 2003, p.20) e prosseguiram com o sorteio, sem o protesto de Whetmore, que teve o infortúnio de ser o sorteado. Após serem tratados, no hospital, por desnutrição e choque, os réus foram indiciados pelo assassinato de Roger Whetmore.

\subsection{O Julgamento}

Depois de concluídos os depoimentos, o representante do júri (um advogado) sugeriu ao tribunal que os jurados emitissem um veredicto especial, deixando para o tribunal decidir, baseado nos fatos, achar os réus culpados. O Promotor de Justiça e o Advogado de Defesa acataram, após alguma ponderação, o procedimento apresentado. Em um longo e especial veredicto, os jurados acharam que os fatos, como relatados acima, e, ainda, decidiram que se, baseando em tais fatos, os réus fossem culpados, e o crime imputado a eles, então os jurados considerariam os réus culpados.Com base nesse veredicto, o juiz, presidindo a seção, achou por bem exarar a sentença de que os réus eram culpados pela morte de Roger Whetmore.(FULLER, 2003, p.21).

Baseado nesse veredicto o juiz sentenciou que os réus deveriam ser condenados à morte pela forca baseando-se no seguinte estatuto: "Qualquer um que, de própria vontade, retira a vida de outrem, deverá ser punido com a morte”. Esse estatuto não permite exceções, nem mesmo diante das singularidades de um caso como este. 
Após sua liberação, os jurados enviaram uma solicitação ao Chefe do Executivo requerendo a comutação da pena aplicada aos réus para a prisão de seis meses, usando para isso o pedido de Clemência.O juiz do Tribunal de Primeira Instância do Condado de Stowfield, responsável pela decisão apresentada acima, também se uniu a tal solicitação. No entanto o Chefe do Executivo não se manifestou a respeito, provavelmente, aguardando a decisão do Tribunal de Apelações, ao qual os réus recorreram após a decisão do Tribunal de Primeira Instância.

\subsection{Teses Apresentadas}

No Tribunal de Apelações, composto pelos juízes, Truepenny, Foster, Tatting, Keen e Handy, as seguintes teorias foram apresentadas:

\subsubsection{Clemência}

Devido à singularidade do presente caso o Presidente do Tribunal de Apelações, Truepenny, reiterou o pedido de Clemência ao Executivo.Para isso fez uma longa exposição do caso e a seguir afirmou ser o pedido de Clemência o único dispositivo legal possível, para a resolução do caso, capaz de fazer Justiça e não ferir a Lei.

O juiz ainda faz uma reflexão sobre os rigores do estatuto, que, mesmo diante de caso tão singular, não permite exceções, afirmando que “... o princípio da clemência exercida pelo poder executivo parece-me, admiravelmente, casado com a intenção de mitigar os rigores da lei,...” (FULLER, 2003, p.22). Feitas tais considerações, recomendou a seus colegas que se unissem à solicitação feita ao Chefe do Executivo, ressaltando, que haveria agilidade na resolução do caso, pois este, caso resolvesse tomar outra decisão teria que fazer novas audiências, o que seria incompatível com sua função.

\subsubsection{Inocência na visão de Foster}

Os primeiros argumentos em defesa da Inocência, para este caso, foram defendidos pelo juiz Foster. Afirma Foster, que este caso não se rege pelo direito positivo, mas pelo Direito Natural, a "lei da natureza”, como ele denomina; segundo o juiz os réus agiram em estado de necessidade.Defende que o Direito Positivo só pode existir perante a possibilidade de coexistência entre os homens, o que, segundo Foster, não foi possível neste caso.Portanto, cessando essa condição, cessa a vigência do Direito Positivo. 
Outro argumento de igual relevância seria o fato de dez trabalhadores haverem perdido a vida na tentativa de resgatar os cinco exploradores presos.Com que fundamentos seriam, os réus, considerados culpados por terem sacrificado Whetmore em detrimento da sua sobrevivência, se por analogia esses casos são semelhantes? Pois o mesmo bem jurídico estava em jogo: a vida.

O último argumento é o de que, embora a lei não preveja qualquer tipo de exceção, estabeleceu-se, há séculos, que matar em legítima defesa é escusável, o que ocorre pelo fato de que, se a exceção, no que diz respeito à legítima defesa, não é conciliável com as palavras da lei, o é com seu propósito ou finalidade; assim sendo, os mesmos fundamentos lógicos deveriam ser aplicados ao caso sob julgamento. Do mais afirma que: "Se este Tribunal declarar que estes homens cometeram um crime, nossa lei será condenada no tribunal do senso comum, inobstante o que aconteça aos indivíduos interessados neste recurso de apelação”.(FULLER, 2003, p.23).

\subsubsection{Abstenção}

Defendida pelo juiz Tatting, a Abstenção reflete a impossibilidade de se achar uma solução que respeite o espírito da lei, seu propósito, sendo um deles o da prevenção. Após uma análise do parecer do colega Foster, o juiz reconhece que, à primeira vista, seus argumentos são bastante convincentes, ressaltando a citação do precedente daquele Tribunal quanto à legítima defesa, porém, tece-lhe duras críticas, acusando-o de proferir falácias e contradições, especialmente quando contesta o colega quanto ao momento em que os réus passaram do estado de sociedade, para o “estado de natureza”.

Cita, por exemplo, o caso do cidadão que foi indiciado por roubar pão, alegando que estar em condição famélica.Argumentou que se a fome não justificava roubo de alimentos comuns como o pão, também não justificaria um assassinato precedido de canibalismo.

Porém, durante toda sua explanação, ressalta que está acometido de uma dubiedade de sentimentos, entre o que ele chama de lado emocional e lado racional.Quando tendia a defender os réus, era levado a reprovar o seu ato, porém, ao mesmo tempo não se via em condições de condenálos por estes.Posto que, declarou ser incapaz de proferir alguma decisão sobre o presente caso. 


\subsubsection{Acusação}

Posicionamento único neste julgamento foi defendido pelo juiz Keen. Sua primeira consideração repousa na insinuação de que o pedido de Clemência, se acatado, causaria confusão das funções do Executivo e Judiciário e ainda acusa o juiz Truepenny de fornecer instruções, sobre a concessão ou não da Clemência, ao Chefe do Executivo. Em seguida, pronunciou-se no sentido de que, a função do juiz, é aplicar a lei como está escrita. Com essa afirmação, acaba por sacrificar o espírito da lei, excluindo o sentido desta, o objetivo pelo qual foi elaborada.

Por fim, firma-se no sentido de que a resolução do caso deve ser tomada, analisando-se, somente, se os réus agiram intencionalmente ou não e opta pela confirmação da intencionalidade, concluindo que os réus devem ser condenados à morte, seguindo o que diz o estatuto: “Qualquer um que, de própria vontade, retira a vida de outrem, deverá ser punido com a morte".

\subsubsection{Inocência na visão de Handy}

O último julgador a dar seu parecer foi o juiz Handy, que depois de fazer uma síntese dos argumentos de seus antecessores, observa que o Judiciário, dentre os poderes, era o que mais se afasta da realidade social, do homem comum, pois se prende a juízes e casos concretos. Defende a humanização do Judiciário e o uso do senso comum como forma de julgar e aplicar penas. O cerne de sua decisão encontra-se no apoio que o ministro concede à opinião pública, baseando nesta a sua decisão.Ressalta que noventa por cento da população apóia a absolvição dos réus ou, pelo menos, a aplicação de uma pena simbólica.

\subsection{Críticas às Demais Teorias}

Quando da primeira teoria, Inocência, que visa à absolvição dos réus, o juiz Foster argumenta que os réus estariam no que ele chama de "estado de natureza”, que também pode ser entendido como estado de necessidade.Afirma que, nesse estado, não haveria coexistência pacífica entre a vítima e os réus, portanto não estariam sob o manto do Direito Positivo.

Da analise do caso, vê-se que houve, sim, essa coexistência pacífica e que no momento da morte de Roger Whetmore, os réus não estavam oscilando entre a vida e morte, o que caracterizaria o "estado de natureza”. Observou-se que no vigésimo dia da sua entrada na caverna, 
os exploradores ainda dispunham de alimentos.Considerando-se que expedições desta natureza são de curta duração, portando os suprimentos levados são em pequena quantidade, e que os exploradores vinham racionando os alimentos há dias, nota-se que, como Roger Whetmore, foi morto no vigésimo terceiro dia, não é possível que os suprimentos tenham se esgotado tão rapidamente, lembrando ainda que os réus não tinham interesse em acabar os alimentos imediatamente, levando-os a um ato tão reprovável. Quanto à alegação de legítima defesa, feita pelo mesmo julgador, vê-se que esta também não procede. O Código Penal Brasileiro define legítima defesa em seu Art. 25: “Entende-se em legítima defesa quem, usando moderadamente dos meios necessários, repele injusta agressão, atual ou iminente, a direito seu ou de outrem”.

Em nenhum momento foi relatada qualquer agressão aos réus, por parte da vítima, o que descaracteriza a alegação de legítima defesa.

Quanto à Abstenção, defendida pelo juiz Tatting, a crítica mais relevante seria à própria Abstenção, pois esta reflete a ausência de decisão, o que é incompatível com a função julgadora do juiz.Goffredo Telles Junior (2001, p.363) lembra-nos que o juiz julga e esta é a sua missão, portanto é inaceitável que o juiz Tatting escuse-se de sua função. Pela Inocência, pela Culpa, ou pela Clemência, deveria o juiz decidir-se.

No entanto, preferiu o julgador utilizar-se do Argumentum ad Hominem e atacar o seu colega Foster, acusando-o de proferir falácias e contradições.

A teoria da Culpa, defendida pelo juiz Keen, fere completamente a Hermenêutica Jurídica, quando declara que as leis devem ser aplicadas tal e qual estão no papel.Carlos Maximiliano (2003, p.1) ensina que Hermenêutica Jurídica é a sistematização dos processos aplicáveis para a determinação do sentido e alcance das expressões do Direito. Sentido esse, que é o espírito da lei, o porquê de ela ter sido elaborada. São Tomás de Aquino lembra-nos que a letra mata, mas o espírito vivifica. Um verdadeiro juiz, ao relacionar a lei a um caso concreto, aprimora o texto da lei com a Lógica do Razoável, revelando o sentido apropriado para a vida real, e que conduza a uma decisão reta.

A segunda teoria da Inocência, explanada pelo juiz Handy, tem sustentação tendenciosa, ao sugerir que os réus sejam inocentados, porque as pesquisas de opinião pública apontam que noventa por cento é favorável a essa decisão. 
Surge dessa sugestão o questionamento: e se a opinião pública estivesse na orientação contrária, pela condenação? Continuaria o juiz a considerá-la? O que se observa nesta teoria é outra tentativa de absterse da obrigação julgadora do juiz. Como o próprio juiz afirma, a opinião pública é caprichosa, emocional e leva em conta falsas verdades.Em uma pesquisa como esta, muitos dos entrevistados respondem por responder,sem pesar os prós e contras.Sua resposta é sempre impregnada de preconceitos, dos quais deve abster-se quem de fato julga.Portanto a opinião pública não deve ser sustentação de uma sentença que decidirá a vida de quatro pessoas.

\section{$\checkmark \mathrm{O}$ Sentido da Clemência}

O pedido de Clemência, no presente caso, está apresentado pela comutação da sentença de pena de morte, para uma prisão de seis meses e se sustenta pela singularidade deste. Primeiramente, defende-se esta solução daqueles que afirmam ser o pedido de Clemência, um causador de confusão das funções governamentais, confundindo as funções do Executivo e do Judiciário. Ao requerer a Clemência para os réus, o juiz Trueppeny não transfere sua função de julgador para o Chefe do Executivo, ele já proferiu sua decisão ao unir-se aos jurados e ao juiz que expediu a primeira decisão, ao pedir a Clemência.Cabe ao Chefe do Executivo conceder ou não esta premissa que lhe é conferida.Em resumo, o juiz já julgou ser a Clemência a melhor solução.

A Clemência se coloca como um meio termo entre a inocência e a culpa, pois, irá punir os réus por terem assassinado Roger Whetmore, com a prisão de seis meses, mas não desconsiderará os motivos que os levaram a praticar tal ato, o que acontecerá se o estatuto: “Qualquer um que, de própria vontade, retira a vida de outrem, deverá ser punido com a morte", for aplicado.

Para quem defende a Clemência, os réus são culpados e não culpados ao mesmo tempo. A culpa se apresenta de três maneiras: não havia estado de necessidade, nem distúrbios psicológicos que cessassem a capacidade de discernimento e o assassinato em si. O estado de necessidade se descaracteriza, pois no vigésimo dia de sua entrada na caverna, os réus ainda dispunham de alimentos e somente três dias se passaram até o assassinato e antropofagia de Roger Whetmore.Considerando-se que os exploradores 
vinham racionando alimento há dias, três dias não seriam suficientes para acabar o que restava, portanto os réus não estavam oscilando entre a vida e a morte, portanto não houve estado de necessidade.

Também não procedem as alegações de ausência de discernimento provocada por distúrbios psicológicos, questão suscitada quando da apresentação do trabalho original. É evidente que os réus passavam por condições que os dispunham à tortura psicológica.A privação, a falta de perspectivas, tudo os deixava suscetíveis a alterações de comportamento.Contudo, é relevante o fato de terem os réus, em conjunto com a vítima, chegado a um acordo comum para a resolução do problema que se apresentava: a morte em caso de ausência de alimentos.Acordo esse que resultou na morte de Roger Whetmore.

Um dos menores distúrbios mentais, denominado, Transtorno Psicótico Breve, que se refere a uma perturbação mental passageira, poderia ser apontado como causador do ato criminoso.Porém, observa-se que seus sintomas não são compatíveis com o comum acordo a que chegaram os réus e a vítima. Por último analisaremos o elemento de culpa mais óbvio, porém extremamente peculiar, o assassinato.

É inegável que os réus assassinaram Roger Whetmore e realizaram tal ato com vontade.Eles levaram a parte prática do crime a cabo.

Porém o crime não é só prático, ele é também idéia.Antes de alguém que o pratique, ele necessita de alguém que o idealize, que o planeje, que tenha intenção de levá-lo à diante. No caso, é evidente que, se houve alguém que planejou o assassinato, esse alguém foi Roger Whetmore, a vítima. Ele foi o que o fenômeno "vitimologia" denomina de vítima coadjuvante e cooperadora, aquela que por imprudência ou má-fé, influencia para sua vitimização. Ora, se assassinato é idéia e prática, e os réus executaram somente a parte prática do crime, não podem ser condenados pelo estatuto que pune o assassinato.Além do mais, o estatuto fala em "própria vontade", que pressupõe intenção, que pressupõe planejamento, parcela do crime não executada pelos réus, logo o estatuto não se aplica.

Vontade é algo mais forte que a intenção, éinerente à impulsividade.A intenção é algo mais metódico, planejado.Vejamos no caso da legítima defesa, repelese uma agressão injusta por vontade, pois é algo inerente ao momento. 
Os réus agiram por vontade, não por intenção.E, portanto não podem ser condenados pelo estatuto citado, que apena com a morte quem de "própria vontade”, ou seja, intencionalmente, retira a vida de outrem.

O assassinato é um elemento peculiar, pois apresenta e exclui a culpa dos réus. Do mais, não procedem as tentativas de defesa baseadas no contrato estabelecido entre as partes dentro da caverna, por se tratar de um objeto ilícito: a vida humana.Revoga-se, assim, parte da argumentação defendida no trabalho original. Algumas considerações quanto à inflexibilidade do estatuto já citado, são pertinentes.O seu rigor ignora as particularidades de cada caso, não realizando o que ensina Carlos Maximiliano (2003, p.5),quanto à aplicação do Direito,que seria aplicar a cada caso concreto a norma adequada. O estatuto é, ainda, questionável, pois como pode existir punição com a morte em uma sociedade que tanto recrimina a retirada da vida humana? Como bem lembra Cesare Beccaria (2003, p.49), "os castigos têm por finalidade única obstar o culpado de tornar-se futuramente prejudicial à sociedade e afastar os seus concidadãos do caminho do crime”, então como a função realizar-se-á se o cidadão estará morto? Como provará que não é mais prejudicial?

Este estatuto, além de inaplicável ao caso, é também inaceitável dentro da sociedade onde vigora. Já dizia Santo Agostinho “detesto o pecado, não os pecadores".

\section{CONCLUSÃo}

Conclui-se, portanto, que a Clemência não é um instrumento que cause confusão entre as funções Executiva e Judiciária. Ela é uma forma auxílio mútuo entre os dois poderes. A decisão de um será completada pela concessão ou não do preceito que o outro possui. Sendo assim pode, tranqüilamente, ser uma forma de se decidir o presente caso.

É a Clemência, uma forma sensata de decidi-lo. Pois fará cumprir-se a função da pena, mas não ignorará os motivos que levaram os réus a praticar o ato que os tornou culpados. Observando as demais teorias, viu-se que suas bases são inválidas.

A Inocência defendida por Foster, não houve estado de necessidade, pelo curto espaço de tempo entre a declaração, por parte dos exploradores, de 
que ainda possuíam provissões e o assassinato de Roger Whetmore.Tão pouco houve legítima defesa já que não houve injusta agressão da vítima em relação aos réus.

A Abstenção do juiz Tatting por si é condenável, pois, por ser ausência de decisão, não faz cumprir-se a missão julgadora do juiz.

A Acusação, teoria do juiz Keen, vai totalmente contra a Hermenêutica Jurídica, quando nega interpretação ao estatuto aplicável a casos de assassinato.

A Inocência, defendida pelo juiz Handy, com base na opinião pública, é condenável por se basear em julgamentos impregnados de preconceitos, dos quais deve abster-se o julgador.

Desta forma, sendo as demais teorias fundamentadas em argumentos questionáveis, conclui-se que a solução adequada para o presente caso é a Clemência, por conciliar a legalidade com a humanidade e por melhor aplicar a norma escrita ao caso concreto.

\section{Anexos}

\subsection{Função dos Anexos}

Os presentes anexos têm como objetivo primaz, fornecer, a título de consulta, os elementos científicos utilizados nas pesquisas deste trabalho, a despeito do hipotético perfil de comportamento dos espeleólogos durante o tempo em que estiveram enclausurados na caverna, e são fulcrados em definições técnicas e experimentais reais, retirados da literatura médica e científica.

\subsection{Anexo 1 - Transtorno Psicótico Breve}

O Transtorno Psicótico Breve pode ter um quadro muito parecido com o da Esquizofrenia ou com o Transtorno Esquizofreniforme, apresentando delírios, alucinações, linguagem ou comportamento desorganizado, ou com o Transtorno Delirante. Entretanto, esses sintomas deverão estar presentes por um curto espaço de tempo e persistir no mínimo por um dia, e no máximo por um mês, melhorando completamente dentro desse período.

Nos delírios o indivíduo crê em idéias falsas, irracionais ou sem lógica. 
Em geral são temas de perseguição, grandeza ou místicos. Já nas alucinações, o paciente percebe estímulos que na verdade não existem, como ouvir vozes ou pensamentos, enxergar pessoas ou vultos.

A linguagem ou pensamento desorganizado resulta em o paciente falar de maneira ilógica e desconexa, demonstrando uma incapacidade de organizar o pensamento em uma seqüência coerente. Geralmente, encontramos situações estressantes que precipitam o quadro dos sintomas acima. O tratamento deve ser com medicações antipsicóticas, eventualmente necessitando internação hospitalar. A evolução desses quadros costuma ser benigna com total remissão dos sintomas.

\subsection{ANEXo 2 - VITIMOLOGIA E A CLASSIFICAÇão DAS VÍtIMAS - SEGUNDO Von HeNTIG}

Não há unanimidade entre os estudiosos do fenômeno da vitimologia de ser ela uma ciência autônoma ou apenas um ramo recente da Criminologia. Diversos autores, dentre eles o próprio Benjamin Mendelson, posicionam-se a favor da autonomia científica. A maioria, porém, inclina-se para uma posição mais moderada, entendendo-a como um ramo da Criminologia, mas com possibilidade efetiva de tornar-se ciência. Lola Aniyar de Castro, criminóloga venezuelana, considera: "ainda em seu estado atual de simples hipótese de trabalho, como objeto de uma possível ciência autônoma”. Israel Drapkin, diretor do Instituto de Criminologia da Faculdade de Direito da Universidade Hebraica de Jerusalém, entende que o fenômeno da vitimologia referese ao estudo da vítima, e é precisamente essa definição plural a que credencia a possibilidade do estudo do sujeito desde um grande número de aspectos diferentes e antagônicos. Para Mendelson, a finalidade é o estudo da personalidade da vítima, tanto de seu comportamento delinqüente como de suas inclinações subconscientes.

Ellenberger, por sua vez, a conceitua como sendo um ramo da Criminologia que se ocupa da vítima direta do crime e que compreende o conjunto de conhecimentos biológicos, sociológicos e criminológicos a ela concernentes. Paul Cornil a compreende como o estudo da personalidade da vítima, de seu comportamento, suas motivações e reações, em face de uma infração penal. Para Raul Goldstein, seria parte da Criminologia que estuda a vítima não como efeito conseqüente da 
realização de uma conduta delitiva, mas como uma das causas, às vezes principal, que influenciam na produção de um delito.

Guglielmo Gulotta define vitimologia como uma disciplina que tem por objeto o estudo da vítima, de sua personalidade, de suas características, de suas relações com o delinqüente e do papel que assumiu na gênese do delito. Eduardo Mayr assinala que é o estudo da vítima no que se refere a sua personalidade, quer do ponto de vista biológico, psicológico e social, quer do de sua proteção social e jurídica, bem como dos meios de vitimização, sua inter-relação como vitimizador e aspectos interdisciplinares e comparativos.

Outrossim, acreditamos ser, a vitimologia, um ramo da Criminologia que estuda cientificamente as vítimas visando adverti-las, orientá-las, protegê-las e repará-las contra o crime.

\section{Classificação das vítimas segundo Von Hentig:}

a) vítima resistente

b) vítima coadjuvante e cooperadora

Pode-se citar, na primeira hipótese, a legítima defesa em que a vítima reage a uma injusta agressão e, na segunda, os casos em que a vítima, por imprudência ou má-fé, concorre para a produção do resultado (FILHO, 2004, p.49). 


\section{Bibliografia}

ROSSI, João Paulo. O Caso dos Exploradores de Cavernas. Introdução e Apêndice. Livraria e Editora Universitária de Direito, 2003.

FULLER, Lon L. O Caso dos Exploradores de Cavernas. Livraria e Editora Universitária de Direito, 2003.

JUNIOR, Goffredo Telles. Iniciação na Ciência do Direito. Ed. Saraiva, 2001.

MAXIMILIANO, Carlos. Hermenêutica e Aplicação do Direito. 19a edição. Ed. Forense, 2003.

FILHO, Guaracy Moreira. Vitimologia: o papel da vítima na síntese do delito. $2^{a}$ edição. Ed. Jurídica Brasileira, 2004.

BECCARIA, Cesare. Dos delitos e das penas. $1^{\mathrm{a}}$ edição. Ed. Martin Claret, 2003.

ABUCHAIM, Ana Luiza Galvão. ABUCHAIM, Cláudio Moojen. Esquizofrenia e outros transtornos psicóticos. ABC da Saúde, Porto Alegre, nov. 2001. Disponível em: <http://www.abcdasaude.com.br/artigo.php?189>. Acesso em: 16 set. 2004. 